\title{
РАЗВИТИЕ ЭКОЛОГИЧЕСКОГО ТУРИЗМА В СЕЛЬСКОЙ МЕСТНОСТИ С ПРИВЛЕЧЕНИЕМ ДОМАШНИХ ХОЗЯЙСТВ К ПРОИЗВОДСТВУ ТУРИСТСКОГО ПРОДУКТА
}

\section{Владимир Николашин, Бирута Швагждиене}

Московский государственный институт индустрии туризма имени Ю. А. Сенкевича, Россия, Литовский университет спорта

\section{АННОТОЦИЯ}

В статье описывается процесс развития экологического туризма в сельской местности с привлечением домашних хозяйств к производству туристского продукта. Мировой опыт показывает, что социально-экономическая эффективность экологического туризма наиболее высока именно на местном и региональном уровнях. Поэтому территории могут стать реальным источником новых рабочих мест и дополнительных источников доходов в местную экономику. Развитие экотуризма будет содействовать привлечению в регион международного внимания и инвестиций, что усилит значимость сельской местности.

Ключевые слова: процесс экологического туризма, сельская местность.

\section{ВВЕДЕНИЕ}

Новые социально-экономические условия - становление рыночных отношений и стабилизация жизненного уровня большей части населения - потребовали и иного отношения к домашним хозяйствам, при рассмотрении которых больший акцент делается теперь на экономические и поведенческие моменты их исследования. В соответствии с этими представлениями домашнее хозяйство рассматривается в качестве одного из важных субъектов экономической деятельности, от результатов которого зависит как благосостояние каждой отдельной семьи, так и всего населения в целом. Поэтому для проведения реальных оценок уровня жизни и благосостояния населения сейчас в еще большей степени, чем ранее необходимо рассматривать его, не только в целом, но и в разрезе отдельных домохозяйств, их доходно-имущественных и социально-демографических групп.

Актуальность исследования обусловлена растущей популярностью экологического туризма в мире, весомым потенциалом Российской Федерации для развития данного вида туризма, а также низким уровнем экономического развития домашних хозяйств в сельской местности.

Научная новизна. Определение наиболее социально- и экономически значимых функций домашних хозяйств в развитии экологического туризма в сельской местности, реализуемые в качестве способов адаптации населения к новым условиям жизнедеятельности, а так же комплексная разработка теоретико-практических научно обоснованных рекомендаций по развитию деятельности домашних хозяйств в сельской местности на рынке экологических 
туристских услуг на основе анализа хозяйственной практики, обобщения специальной литературы, изучении зарубежного опыта, выявления путей и источников роста основных показателей туристской деятельности домашних хозяйств.

Практическая новизна. Разработанные в работе методы и подходы смогут быть рекомендованы к использованию при формировании региональных, местных стратегических программ развития экологического туризма, что будет содействовать экономическому росту и улучшению качества жизни сельского населения России. Сформулированные в работе научные положения, выводы и рекомендации смогут быть использованы органами исполнительной власти на федеральном, региональном и местном уровнях для включения в разрабатываемые ими комплексные программы практических мер по повышению качества жизни сельского населения и обеспечения условий для ведения здорового образа жизни.

Цель. Целью исследования является формирование методических основ стратегии развития экологического туризма в России, улучшение экономического состояния отдельных регионов, не имеющих альтернативных возможностей для повышения качества жизни сельского населения и уровня экологической культуры. Определение направлений совершенствования структуры и повышения эффективности вложений населением своих средств в рыночные инновации типа экологического туризма в условиях государственной поддержки.

\section{Задачи:}

1. Анализ существующих определений экологического туризма, выявление базовых принципов и возможных объектов экотуризма, определение его роли и значимости в сфере турбизнеса. Разработка классификации видов и форм экологических туров.

2. Определение социально-экономических факторов и формирование стратегических программных мероприятий, обусловливающих эффективное развитие экотуризма в регионе.

3. Позиционировать экологический туризм на рынке сельских населенных пунктов одновременно как объект инвестирования и потребления. Выявить необходимые условия и ограничения при проектировании экологических туров как средства достижения высокого качества жизни.

4. Предложить приемлемый способ обеспечения финансовой устойчивости экологического туризма с учетом государственного регулирования их хозяйственной деятельности.

5. Сформулировать математическую модель расчета эффективности инвестирования проектов в экологический туризм. Определить критерии оценки эффективности инвестирования проектов экологического туризма их участниками. Выполнить оценку инвестиционных рисков различных вариантов функционирования экологического туризма. 


\section{МЕТОДОЛОГИЯ И МЕТОДЫ ИССЛЕДОВАНИЯ}

Многоплановость исследуемой темы предопределили использование междисциплинарного подхода в качестве методологической основы. Заявленная тема находится на стыке разных дисциплин: истории, экономики, географии, социологии. Исторический характер исследования основывается на принципах историзма и научной объективности, а также анализа фактов, что предусматривает изучение исторических явлений в процессе развития и взаимосвязи с учетом конкретно-исторических условий их возникновения. Указанные принципы обусловили использование совокупности общенаучных (анализ, синтез, дедукция) и специально-научных (историко-генетический, сравнительно-исторический, историко-типологический, историко-системный, проблемно-хронологический) методов исследования.

\section{РЕЗУЛЬТАТЫ ИССЛЕДОВАНИЯ И ИХ ОБСУЖДЕНИЕ}

Реализация возможностей, заложенных в современных производительных силах, требует, прежде всего, новых подходов к раскрытию содержания и роли отношений и форм распределения, обусловливающих эффективное использование рабочей силы и средств производства, эффективное функционирование общественного производства в целом (Батюков, 2000). Так новые социально-экономические условия - становление рыночных отношений и стабилизация жизненного уровня большей части населения.

Интрилигейторф (2003) говорит, что стабилизация определяла границы государственного дефицита и другие элементы макро экономической политики. По его словам, одним из многих последствий неудачи политики стабилизации и последующих за ней депрессии и инфляции является истощение инвестиций, разрушение капитала и отток его за границу. Это сопровождалось массовой безработицей, падением заработной платы и жизненного уровня, ведущих к обнищанию большей части населения. В то время как жизненные условия ухудшались, сеть социального обеспечения сокращалась, поскольку такие услуги государства, как здравоохранение, образование, субсидирование жилья и продуктов питания становятся недоступными для большинства населения. В дополнение, все другие системы социального обеспечения, стандартные для современного государства, такие как охрана окружающей среды, образование, наука и технологии, также приходят в упадок. До сегодняшнего дня эти системы не оправились от шоковой терапии и должны быть восстановлены.

Одной из ценностных установок общества потребления является здоровый образ жизни, физическая активность индивида. По мнению психолога Дичтера (Dichter) (1964, с. 73), решив проблему производства, люди «двинулись дальше, к удовлетворению новых потребностей. Они хотят путешествовать, совершать открытия, быть физически независимыми». Сегодня образ преуспевающего бизнесмена все чаще ассоциируется с мобильностью, готовностью путешествовать с различными целями. А. Тоффлер (1997) отмечает, что для 
постиндустриального общества «ежегодные поездки, путешествия и постоянные перемены места жительства стали второй натурой. Образно говоря, мы полностью «вычерпываем» места и избавляемся от них подобно тому, как мы выкидываем одноразовые тарелки и банки из-под пива... Мы воспитываем новую расу кочевников, и мало кто может предположить размеры, значимость и масштабы их миграции» (Тоффлер, 1997, с. 64).

Значительная часть населения страны в течение последнего десятилетия вынуждена была существовать в тяжелых экономических условиях. В связи с этим многие семьи значительную часть своего времени использовали для организации самообеспечения, включая производство продуктов питания и многих видов услуг, часть которых раньше оказывалась как платная, а также для осуществления индивидуально-трудовой деятельности, мелкой розничной торговли и некоторых других видов собственной предпринимательской деятельности.

Оценка направлений, масштабов и последствий активизации деятельности домашних хозяйств в условиях происходящих социально-экономических преобразований представляется весьма важной и актуальной задачей. Решение этой задачи важно, прежде всего, для придания наиболее рационального и эффективного характера этим процессам, а также с точки зрения обоснования и выработки положений социально-экономической политики, касающейся проблем поддержки семьи и домашнего хозяйства, выбора направлений адаптации населения, социальной защиты малоимущего населения, построения рациональной системы налогообложения.

В последнее десятилетие в России не менее активно развивается наука о туризме. Туризм стал объектом изучения социологов, экономистов, глобалистов. Индустрия туризма занимает значительный сектор макроэкономики, уступая по объемам прибыли лишь нефтяной промышленности и автомобилестроению. Она оказывает немаловажное влияние на миграционные процессы населения, определяя в известной степени демографическую ситуацию планеты, а также способствует обмену социокультурной информацией между сообществами в глобальном масштабе. Несмотря на интенсивное исследование туризма различными отраслями науки, это важное социальное явление по-прежнему остается достаточно мало осмысленным в рамках культурно-философского анализа, равно как и массовая культура. В XX в. масштабы перемен, расширение человеческих горизонтов, появление иных вкусов и потребностей сформировали новый тип личности - человека эпохи потребления. «Охота к перемене мест» изначально присуща человеку, однако лишь в прошлом веке эта потребность была преобразована в коммерческий продукт. Д. Белл (1999) писал, что если «индустриальное общество определяется через количество товаров, обозначающих уровень жизни, то постиндустриальное общество определяется качеством жизни, измеряющееся услугами и различными удобствами - здравоохранением, образованием, отдыхом и культурой, - которые стали желанными и доступными для каждого» (Белл, 1999, с. 171). 
К наиболее перспективным исследованиям, носящим международный характер, относится изучение туризма как социокультурного феномена. Поскольку туризм стал составляющим фактором общественного развития, его можно рассматривать в качестве объекта исторического исследования. Туризм уже давно считается одной из наиболее доходных и интенсивно развивающихся отраслей мирового хозяйства. Сегодня большое внимание выделяется для изучения экологического туризма. Экологический туризм (далее - экотуризм) играет значительную роль в мировой индустрии туризма и гостеприимства. По прогнозам экспертов Всемирной туристской организации (BTO), в XXI веке темпы его роста будут попрежнему высоки, а приносимые доходы внесут значительный вклад в развитие экономик многих стран мира, особенно развивающихся. Это позволит стимулировать социальноэкономический рост в отсталых регионах (Храбовченко, 2003).

Среди основных предпосылок зарождения экологического туризма ведущую роль занимает, усиливающаяся из за массовости туризма, антропогенная нагрузка на природные и культурно-исторические туристские ресурсы. Эта нагрузка возрастает прямо пропорционально темпам роста туристских посещений. По прогнозам, составленным Всемирной туристкой организацией (ВТО), международные прибытия к 2020 г. составят 1,6 млрд. чел., учитывая это, в современных условиях, становится очевидным нарастание противоречий в вопросе удовлетворения туристского спроса и рационального использования туристских ресурсов (Байсултанова, 2012).

В международной практике экологическим туризмом лежат следующие принципы: неистощительное, устойчивое использование природных ресурсов; обеспечение сохранения природного, социального и культурного разнообразия; тщательное планирование, комплексный подход, интеграция экотуризма в планы регионального развития; поддержка местной экономики; участие местного населения в развитии туризма и получение им финансовых и прочих преимуществ от этой деятельности; повышение уровня экологического образования посетителей; тесное сотрудничество организаций различного профиля; обучение персонала; сокращение чрезмерного потребления и затрат (Моралева, Ледовских, 2001).

Линдберг и др. (Lindberg et al., 1998) предлагает использовать более простое и общее концептуальное определение: «экотуризм - это устойчивый и природно-ориентированный туризм и рекреация». Устойчивость же в туризме подразумевает положительный общий баланс экологических, социально-культурных и экономических воздействий туризма, а также положительное воздействие посетителей друг на друга. Таким образом, те виды туристической деятельности, которые имеют наиболее высокий суммарный положительный эффект с точки зрения экологии, экономики и социального развития, являются более устойчивыми. Концепцию экотуризма можно представить в виде следующих базовых принципов (1 рис.).

Таким образом, вместо «жесткого» определения современное понятие экотуризма можно свести к набору принципов, применимых к любым видам туризма, связанным с природой, в том числе и достаточно «массовым» (Ледовских и др., 2012). 


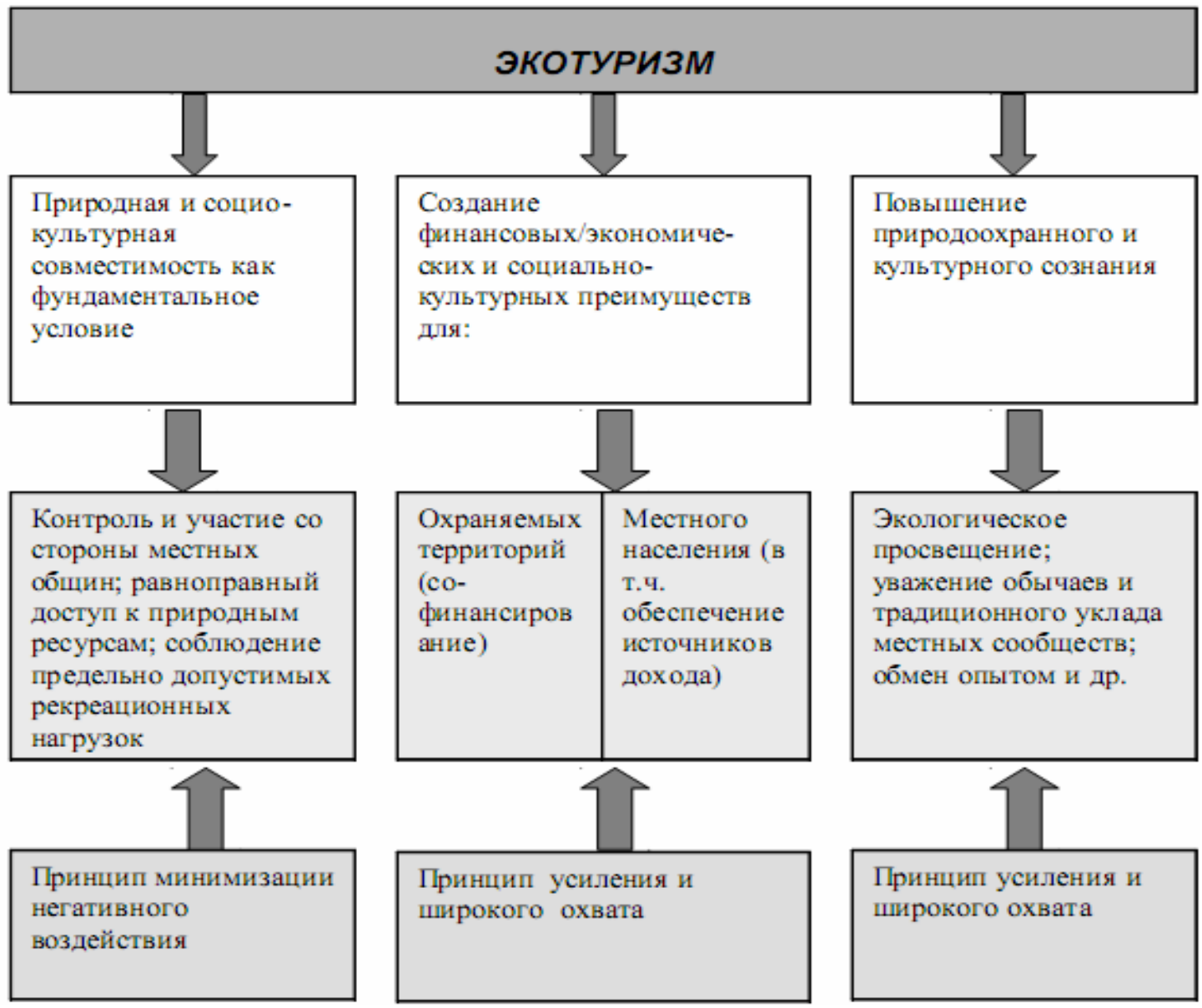

1 рис. Концепция экотуризма (Steck, 1999)

Экотуризм лежит «на пересечении» природоориентированного и устойчивого туризма. Взаимосвязь между перечисленными типами туризма иллюстрирует 2 рис. (Ледовских и др., 2012).

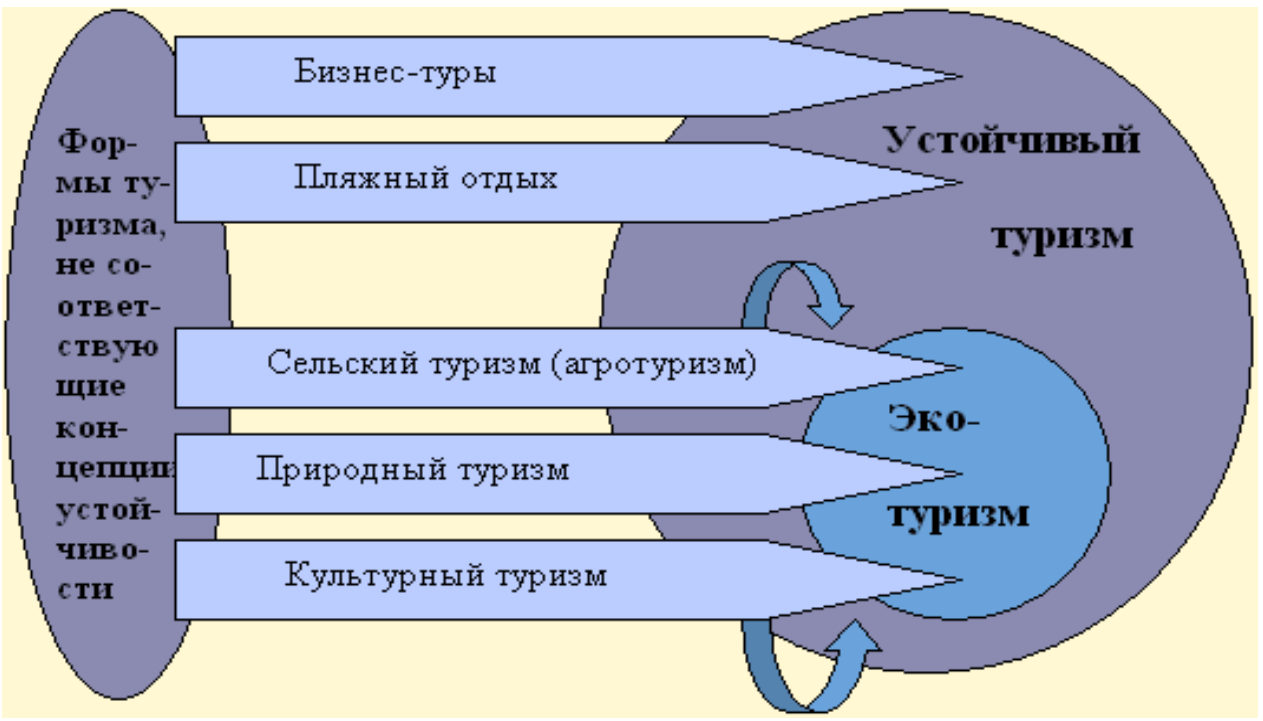

2 рис. Взаимосвязь туризма между типами (Ледовских и др., 2012) 
Таким образом, несмотря на все многообразие видов и форм, экологический туризм отличают следующие особенности: путешествия в места, где сохранилась относительно нетронутая природа и традиционная культура; тщательное планирование, мониторинг и управление с целью недопущения деградации природной и культурной среды; всемерное содействие охране природы посещаемых регионов; детальное знакомство с местными природными и культурно-этнографическими особенностями; сотрудничество с местным населением; создание экономических условий для природоохранной деятельности.

Экотуризм сегодня - это комплексное, междисциплинарное направление, беспечивающее взаимосвязь интересов туризма, охраны природы и культуры, и его роль может быть весьма существенна (Ледовских, Моралева, 2012).

Теме развития экологического туризма посвящен ряд работ российских и зарубежных авторов. К сожалению, в этих трудах отсутствует целостное представление об экологическом туризме как объекте управления, слабо разработан понятийный аппарат, что приводит к неоправданной подмене терминов и проблемам статистического учета. В целом, можно указать на отсутствие понимания специфики экологического туризма как объекта управления, слабое освещение вопросов организации и управления развитием экологического туризма в РФ, а также недостаточную проработку стратегических аспектов развития экологического туризма. В современных исследованиях, посвященных экологическому туризму, отсутствует методология разработки стратегических планов основных участников данного сектора рынка и их интеграции как в общую стратегию развития экологического туризма в регионе, так и в концепцию устойчивого развития всей туристской отрасли. Основная масса научнометодических вопросов управления развитием экологического туризма требует специальных исследований.

\section{Что такое экотуризм: современная концепция?}

Экотуризм стимулирует и удовлетворяет желание общаться с природой, предотвращает негативное воздействие на природу и культуру и побуждает туроператоров и туристов содействовать охране природы и социально-экономическому развитию (Моралева и др., 2008).

В ходе исследования выявлены инфраструктурные, территориальные, производственные и социо-культурные факторы оценки агротуристической привлекательности экотуризма сельских поселений, позволяющие сформировать подходы к управлению спросом (Власенко, 2008). Автором разработан алгоритм оценки агротуристической привлекательности отдельных сельских поселений, основанный на выявлении наиболее привлекательных аспектов предполагаемого агротура и призванный помочь сформировать на начальном этапе деятельности предприятий, предоставляющих услуги агротуризма, спрос на собственный агротурпродукт (3 рис.). 


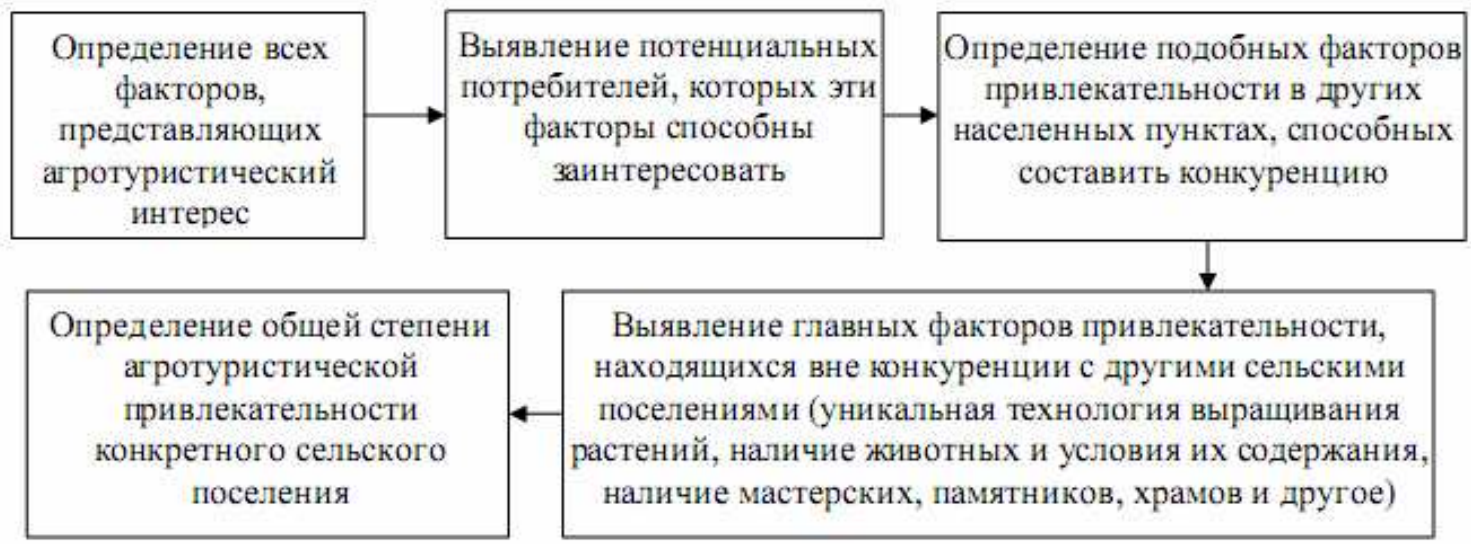

3 рис. Алгоритм оценки агротуристической привлекательности сельского поселения (Власенко, 2008)

Определена социально-экономическая эффективность развития экологического туризма и агротуризма. При определении социально-экономической эффективности развития агротуризма, выделено четыре уровня исследования:

1. Оценка эффективности с позиции государства. Для государства развитие экологического туризма и агротуризма проявляется в увеличении налоговых поступлений от туристической деятельности, улучшении благосостояния и здоровья граждан, возрождении культуры малых народностей.

2. Оценка эффективности с позиции самого хозяйствующего субъекта, предоставляющего услуги агротуризма. Для хозяйствующего субъекта эффективность от агротуристической деятельности проявляется, прежде всего, в получении дополнительного дохода, расширении производства, его диверсификации.

3. Оценка эффективности с позиции жителя сельского поселения. Для сельского жителя эффективность от бизнеса экологического туризма, проявляется в обеспечении занятости; поддержке социально незащищенных слоев населения; улучшении содержания жилищного фонда; расширении рынка сбыта сельхозпродукции; организации досуга и культурно-просветительской работы в сельской местности.

4. Оценка эффективности с позиции туриста. Для туриста эффективность развития агротуристической деятельности проявляется в появлении дополнительного места отдыха, обеспечивающего спокойный отдых в сельской местности, разнообразные природные ландшафты, улучшение здоровья. (Власенко,2008).

Туристическая деятельность стимулирует развитие других отраслей - в первую очередь, сельского хозяйства, легкой промышленности, производства стройматериалов. Доходы от туризма позволяют более эффективно использовать ресурсы и применять более современные технологии (покупать новое оборудование, использовать жидкое горючее вместо дров, повысить образовательный уровень, и тем самым, качество трудовых ресурсов и др.). Все это 
дает значительный импульс для развития экономики и роста благосостояния местных жителей, особенно в районах, удаленных от крупных индустриальных центров, с традиционно низким уровнем экономического развития (Панов, 1998). Домашние хозяйства не только несут затраты в связи с использованием туристской услуги, но и сами могут, и должны оказывать существенное влияние на развитие туристских услуг.

\section{ВЫВОДЫ И ПЕРСПЕКТИВЫ}

Планируемый результат предполагаемы в статье также методы, подходы смогут быть рекомендованы к использованию при формировании региональных, местных стратегических программ развития экологического туризма, что будет содействовать экономическому росту и улучшению качества жизни сельского населения России, а именно:

1. Сформулировать определение, предложить классификацию видов и форм, определить основные базовые принципы развития экологического туризма.

2. Предложить математическую модель создания зоны экотуризма, обеспечивающую сохранение экологического состояния региона.

3. Разработать экономико-математические модели стратегического развития экотуризма, учитывающие, наряду со стабильностью экономических показателей среды, основные факторы взаимодействия возникающих при этом процессов.

4. Обосновать способ обеспечения финансовой устойчивости экологического продукта путем его коммерциализации через развитие сельского туризма, что также одновременно создаст положительную обратную связь между чистотой территории и доходами сельских жителей, в отличие от существующих деревень и дачных объединений, где эта связь отрицательна;

5. Предложить структуру самоуправления экологическим туризмом в сельской местности, обязательным, с точки зрения государства, условием которой должно быть наличие молодежной организаторской команды, оказывающей за счет бюджета все требуемые административные, социальные, культурные, образовательные, медицинские услуги населению;

6. Разработать математическую модель для расчета эффективности инвестиционных проектов экологического сельского туризма, базирующаяся на реальных процессах и исходных данных, позволяющую правильно отразить главные особенности развития экологического продукта во времени;

7. Определить критерии оценки эффективности инвестиционных проектов экологического туризма в сельской местности, основанные на зависимости намерений жителей от всех своих совокупных доходов, а не только от произведенных инвестиций, что обеспечивает принятие ими обоснованных решений об участии в подобных проектах; 
8. Оценка инвестиционных рисков выполненную на основе расчетов различных вариантов, функционирования экологического туризма в сельской местности, выявившая условия устранения дефицита в финансах жителей, возникающего на протяжении нескольких первых лет проживания;

9. Разработать рекомендации по повышению эффективности инвестиционных проектов экологического туризма в сельской местности, состоящие в продвижении на рынок подобных экологических продуктов и гарантированных государством как оздоровительные и экологически чистые.

Область применения (или внедрения) планируемых результатов. Результаты исследования могут быть использованы турфирмами для туроперейтинговой работы и для проведения экскурсий природно-экологической направленности, а также в учебном процессе при подготовке специалистов туристской сферы. Разработанные экономико-математические модели развития экологического туризма рекомендуются для проведения предварительного анализа в процессе формирования стратегии развития экотуризма в конкретных регионах России.

\section{ЛИТЕРАТУРА}

1. Dichter, E. (1964). Handbook of Consumer Motivations. New York: McGraw Hill.

2. Ecotourism and Sustainable Development in Biosphere Reserves. Experiences and prospects. (2002). Quebec, Canada MAB/UNESCO.

3. Guidelines for Community Based Ecotourism Development. (2001). UK, WWF.

4. Lindberg, K., Hawking, D. et al. (Eds.) (1993). Ecotourism: A Guide for Planners and Managers, vol. 1. North Bennnington, Vermont: The Ecotourism Society.

5. Rauschelbach, B., Schäfer, A., Steck, B. (2002). Cooperating for Sustainable Tourism / Kooperieren für Nachhaltigen Tourismus. Kasparek Verlag.

6. Steck, B. (1999). Sustainable Tourism as a Development Option. Practical Guide for Local Planners, Developers and Decision Makers. Eschborn.

7. Байсултанова, Л. Б. (2012). Формирование организационно-экономического механизма управления развитием экологического туризма (на примере Кабардино-Балкарской Республики): автореферат диссертации. Сочи.

8. Батюков, М. В. (2000). Распределительные отношения и уровень жизни населения в условиях перехода к рыночной экономике. Научная библиотека диссертаций и авторефератов. Доступ в интернете: http://www.dissercat.com/content/raspredelitelnye-otnosheniya-i-uroven-zhizni-naseleniya-vusloviyakh-perekhoda-k-rynochnoi-e\#ixzz2Xhth16Vl [дата обращения: 2013-04-09].

9. Белл, Д. (1999). Грядущеее индустриальное общество. Москва.

10. Бочкарева, Т. В., Самарцев, С. Е., Хлыстова, Я. Г. (2002). Эколого-культурный туризм: технологии и опыт организации. Экологический туризм на пути в Россию. Тула.

11. Веснин, В. Р. (1998). Практический менеджмент персонала. Москва: Юрист. Доступ в интернете: http://ecotours.ru/publication_ru/cho_takoje_ecotourism.html [дата обращения: 2013-04-29]. 
12. Власенко, О. В. (2008). Основные направления развития агротуризма в Прибайкалье. Современная деятельность сельскохозяйственных товаропроизводителей и научных организаций в развитии АПК Центральной Азии: сборник материалов международной научно-практической конференции (сс. 158-164). Иркутск.

13. Власенко, О. В. (2008). Роль агротуризма в реформировании сельских подсобных производств: автореферат диссертации. Улан-Удэ.

14. Гусанов, А. А. (2010). Экономика и управление народным хозяйством (экономика, организация $u$ управление предприятиями, отраслями, комплексами - сфера услуг): автореферат диссертации. Москва.

15. Дроздов, А. В. (2005). Основы экологического туризма. Москва: Гардарики.

16. Интрилигейтор, М. (2003). Российская экономика: все еще нуждается в структурных реформах. Информ-бюллетень, выпуск 8, ноябрь. Москва: ЭКААР-РОССИЯ. Доступ в интернете: http://www.finansy.ru/publ/rus/007.htm [дата обращения: 2013-04-16].

17. Ледовских, Е. Ю., Моралева, Н. В. (2012). Сохранение биоразнообразия водно-болотных угодий Нижней Волги. Экологический туризм: информаџионное пособие. Волгоград: Фонд развития экотуризма «Дерсу Узала».

18. Ледовских, Е. Ю., Моралева, Н. В., Дроздова, А. В. (2002). Экотуризм на пути в Россию. Принципы, рекомендаиии, российский и зарубежный опыт. Тула: Гриф и К.

19. Лысикова, О. В., Лысикова, Н. П. (2006). Имиджелогия и паблик рилейшнз в соииокультурной сфере. Москва.

20. Моралева, Н. В., Ледовских, Е. Ю. (2001). Экологический туризм в России. Материаль доклада на конферениии «Экотуризм на пути в Россию» Фонда развития экотуризма «Дерсу Узала». Петрозаводск, апрель. Доступ в интернете: http://www.biodiversity.ru/publications/odp/archive/n3(22)/st09.html [дата обращения: 2013-03-21].

21. Моралева, Н. В., Ледовских, Е. Ю., Келер, Т. и др. (2008). Аборигенный экотуризм: методическое пособие. Москва.

22. Панов, И. Н. (1998). Экологический туризм и его роль в устойчивом развитии территорий. Вестник МГУ, сер. 5. География, № 6.

23. Сергеева, Т. К. (2004). Экологический туризм. Москва.

24. Тоффлер, А. (1997). Футуршок. Санкт-Петербург.

25. Храбовченко, В. В. (2003). Экологический туризм: Учебно-методическое пособие. Москва: Финансы и статистика. 


\title{
THE DEVELOPMENT OF ECO-TOURISM IN RURAL AREA WITH THE PROMOTION OF HOUSEHOLDS TO PRODUCE TOURISM PRODUCT
}

\author{
Vladimir Nikolašin, Biruta Švagždienè \\ Moscow State Institute for the Industry of Tourism n. a. Yuri Senkevich, Russia, \\ Lithuanian Sports University
}

\begin{abstract}
New social-economic circumstances - market relations and stabilization of living level for the larger part of population demanded other attitude to the households, thus why today large attention is paid to the economic and behavioral moments in the research. According to this households are seen as one of the most important subjects in the economy on which results depends the welfare of each family and whole society. Nowadays it is more important than earlier to evaluate the living level and welfare of society in general and as a separate household, their material and social demographical groups. The relevance of the research is based on the growing importance of eco-tourism in the world and in the Russian Federation due to the development of this type of tourism and also due to the level of households economic development in rural area.

Scientific innovation. The determination of the most socially and economically important features of households in the development of eco-tourism in rural areas is implemented as methods of adapting to the new conditions, as well as the development of a comprehensive theoretical and practical evidence-based recommendations for the development of the households in rural areas in the market eco-tourism services based on the analysis of economic practices, summarizing the literature, the study of foreign experience, identifying ways and sources of growth in key indicators of tourist activity of households.

Practical innovation. Methods and approaches developed in this work could be recommended for use in the formation of regional and local strategic programs for the development of eco-tourism what will promote economic growth and improve the quality of life of the rural population of Russia. Scientific statements, conclusions and recommendations formulated in this work could be used by the executive authorities in the federal, regional and local levels to include complex programs in the development of practical measures in order to improve the quality of life of the rural population and ensure the conditions for a healthy lifestyle. The aim of the study is to develop methodological principles of eco-tourism development strategy in Russia, improving the economic performance of individual regions without alternative opportunities to improve the quality of life of the rural population and the level of environmental culture. Main trend is to improve the structure and efficiency of public investments in market innovations for the development of eco-tourism with the state support.
\end{abstract}

Keywords: the process of eco-tourism, rural area, economy effect of households. 